\title{
Steatorrhoea in rats with an intestinal cul-de-sac
}

\author{
P. P. HOET ${ }^{1}$ AND H. EYSSEN \\ From the Rega Institute for Medical Research, University of Louvain, Louvain, Belgium
}

\begin{abstract}
EDITORIAL SUMMARY Steatorrhoea in rats with an intestinal cul-de-sac is mainly due to malabsorption of alimentary fats but faecal lipids of endogenous origin are also increased. Steatorrhoea depends on the site of the blind loop in the small intestine and is mainly caused by bacterial proliferation in the lumen of the gut. The aetiological role of Gram-positive anaerobic microbes, especially Clostridium welchii, is suggested.
\end{abstract}

Malabsorption of fat is a prominent feature in patients with anatomical lesions of the small intestine (Badenoch, 1960), as in strictures, multiple diverticulosis (Cooke, Cox, Fone, Meynell, and Gaddie, 1963), entero-enteric fistulas, and surgically produced blind loops (Goldstein, Wirts, and Kramer, 1961). Malabsorption of vitamin $B_{12}$ occurs independently or in association with steatorrhoea and can lead to a megaloblastic anaemia (Gellman, 1956).

The structural abnormalities of the intestine in the blind loop syndrome cause stasis and microbial proliferation in the lumen of the gut. In patients suffering from blind loop syndrome, high bacterial counts were found in aspirated material from the afferent loop in contrast to the transient flora of a normal small intestine (Wirts and Goldstein, 1963). Further evidence of the bacterial aetiology is provided by the therapeutic effect of broad-spectrum antibiotics or surgical correction of the structural defect.

Surgically formed small intestinal cul-de-sacs in rats and in dogs provided an experimental approach to the malabsorption of vitamin $B_{12}$ and showed the role of bacterial proliferation in this condition (Cameron, Watson, and Witts, 1949). The increased faecal fat excretion in these animals was recognized (Aitken, Badenoch, and Spray, 1950).

The purpose of this investigation was to study the fat absorption and excretion in rats with surgically produced blind loops. The effect of different antibiotics on fat excretion was correlated with bacteriological findings in order to identify the organism or organisms responsible for this experimental steatorrhoea.

\section{MATERIALS AND METHODS}

EXPERIMENTAL ANIMALS AND DIETS Male rats, each weighing 150-200 g., from a stock colony were used.

'Aspirant aan het Nationaal Fonds voor Wetenschappelijk Onderzoek (N.F.W.O.).
A cul-de-sac was produced surgically on the small intestine under ether anaesthesia, according to the method of Cameron, Watson, and Witts (1950). This self-filling loop, 7 to $8 \mathrm{~cm}$. long, became dilated by the action of peristalsis on the intestinal contents. Most of the animals supported the operation well and lived for more than 15 months. Operated and control animals were kept in individual cages with a wire screen bottom in order to reduce coprophagy and to facilitate collection of faeces. Adaptation to the diet was allowed for at least five days before faeces were collected. The basal composition of the diets is given in Table I.

TABLE I

BASAL COMPOSITION OF DIETS

\begin{tabular}{lr} 
& $\%$ \\
\hline Sucrose & $70 \cdot 5$ \\
Casein & $25 \cdot 0$ \\
Vitamins and choline & $1 \cdot 3$ \\
Mineral salts & $3 \cdot 0$ \\
Chromium oxide & $0 \cdot 2$
\end{tabular}

To obtain a fat-containing diet, $9 \%$ corn-oil $(w / w)$ was added to the basic diet, at the expense of sucrose. In some experiments, animal feed doses of antibiotics (200 parts per million) were added to the $9 \%$ corn-oil diet. Chromium oxide was mixed with all diets and the amount determined in the faeces served as a measure of the amount of food ingested per gram faeces produced. Daily food intake of controls and of rats with a proximal blind loop was also determined, and the total faecal output per 24 hours was calculated.

ANALYTICAL METHODS Faeces were dried in vacuo over phosphorus pentoxide. Free fatty acids and total fatty acids were measured in faeces according to the method of van de Kamer, ten Bokkel Huinink, and Weyers (1949). The petroleum ether extract was titrated with $0.1 \mathrm{~N}$ $\mathrm{NaOH}$, an alcohol-water solution of thymol-blue being used as indicator, and the two phases mixed by bubbling $\mathrm{N}_{2}$ (Dole and Meinertz, 1960).

Free and esterified fatty acids were analysed by liquid gas chromatography after separate extraction (Evrard, 
Hoet, Eyssen, Charlier, and Sacquet, 1964). Chromium oxide was measured in faeces according to the method of Edwards and Gillis (1959).

BACTERIOLOGICAL METHODS The abdomen was opened under ether anaesthesia, and the blind loop was removed. The wall of the loop was incised, and the liquid content was collected. After application of Gram's stain to this material, successive dilutions were made with sterile saline.

Different media were inoculated with the final dilutions: pour plates of $10 \mathrm{ml}$. brain heart infusion agar (B.B.L.) with $0.5 \%$ yeast extract and $10 \%$ bovine blood; S.F. medium (B.B.L.), for the detection of faecal streptococci (enterococci); Tergitol 7 agar (Difco) for members of the coliform groups; Rogosa SL broth (Difco), a selective medium for the cultivation of lactobacilli; reinforced clostridial agar (Oxoid) for anaerobes, especially of the Clostridium species; brain heart infusion agar (B.B.L.) with $0.5 \%$ yeast extract and $0.5 \% \mathrm{Na}-$ thioglycolate for total anaerobic counts. After 24 to 27 hours' growth on these media, colonies were enumerated, examined after being stained by Gram's method, and eventually isolated.

HISTOLOGICAL METHODS Fragments of the blind loop, stomach, jejunum, and ileum were fixed either in formolsaline or in Bouin. After paraffin embedding the following staining methods were routinely applied: haematoxylin, trichrome Masson, and Gram's stain. Several sections were stained by the silver impregnation method of Tibor-Pap and by the P.A.S. stain.

\section{RESULTS}

THE EXPERIMENTAL STEATORRHOEA In three groups of rats an intestinal cul-de-sac was produced respectively on the proximal, middle, or distal part of the small intestine. The rats were fed a $9 \%$ corn-oil diet, and faecal fat was determined one and five weeks after operation. As shown in Table II, the steatorrhoea was maximal when the cul-de-sac was on the proximal part of the intestine, whereas the fat excretion of animals with a distal cul-de-sac was similar to that in normal rats.

In further experiments, only rats with proximal blind loops were used. In these animals the steatorrhoea developed soon after operation, as shown by the figures for faecal fat on the seventh post-operative day and by the increase in faecal fat between the first and fifth week after operation. The difference between control and operated animals was even more pronounced when results were expressed as daily faecal fat excretion rather than as fat content per gram faeces.

To compare the absorption of alimentary fat in control and blind loop rats, the animals were fed a fat-free or a $9 \%$ corn-oil diet, and free fatty acids
TABLE II

FAECAL OUTPUT IN RATS WITH A BLIND LOOP AT THE PROXIMAL, MIDDLE, OR DISTAL PART OF THE SMALL INTESTINE

\begin{tabular}{|c|c|c|c|c|}
\hline \multirow{2}{*}{$\begin{array}{l}\text { Animals } \\
\text { Control }\end{array}$} & \multicolumn{2}{|c|}{$\begin{array}{l}\text { Fat (mg./g. faeces) } \\
\pm S . D .(N)\end{array}$} & \multirow{2}{*}{$\begin{array}{l}\text { Faeces } \\
\text { (mg./24 hr.) } \\
\pm S . D .(N) \\
537 \pm 63(8)\end{array}$} & \multirow{2}{*}{$\begin{array}{l}\text { Fat } \\
(m g . / 24 h r . \\
39\end{array}$} \\
\hline & $87 \pm 22(8)$ & $76 \pm 12$ & & \\
\hline Blind loop & $\begin{array}{l}\text { One Week } \\
\text { Post- } \\
\text { operatively }\end{array}$ & $\begin{array}{l}\text { Five Weeks } \\
\text { Post- } \\
\text { operatively }\end{array}$ & & \\
\hline $\begin{array}{l}\text { Proximal } \\
\text { Middle } \\
\text { Distal }\end{array}$ & $\begin{array}{c}186 \pm 57(7) \\
134 \pm 49(5) \\
75 \pm 9(5)\end{array}$ & $\begin{array}{l}241 \pm 42 \\
165 \pm 25 \\
110 \pm 25\end{array}$ & $\begin{array}{l}780 \pm 104(7)^{1} \\
-\end{array}$ & $\begin{array}{l}166^{1} \\
-\end{array}$ \\
\hline
\end{tabular}

${ }^{1}$ Values determined between one and five weeks after operation.

and total fatty acids were determined in faeces. The results are given in Figure 1.

Fat excretion in control animals was relatively independent of fat intake, whereas in blind loop rats it increased proportionally to alimentary fat, indicating a malabsorption. The faecal lipids of nonalimentary origin were also increased in blind loop rats, since even on a fat-free diet they excreted $30 \%$ more fat than did control animals.

On a corn-oil diet, the proportion of faecal free and esterified fatty acids was the same in control and blind loop rats. On a fat-free diet, control and blind loop rats excrete the same amount of free fatty acid, the difference in total fat being made up of esterfied fatty acids. The faecal free fatty acids, as shown by gas liquid chromatography, contained the oddnumbered, branched fatty acids, in both normal and blind loop rats; these acids are derived from bacterial bodies, as was found in faeces of normal rats (Evrard, et al., 1964).

THERAPEUTIC EFFECT OF ANTIBIOTICS ON EXPERIMENTAL STEATORRHOEA The therapeutic effect of antibiotics

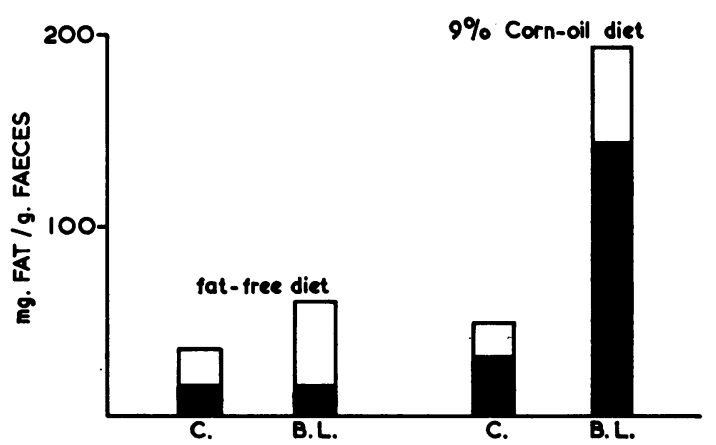

FIG. 1. Faecal fat in control and blind loop rats on a fat-free and a $9 \%$ corn-oil diet. $C=$ control rats; B.L. $=$ blind loop rats: black area indicates free fatty acids. 
on the experimental steatorrhea was investigated to establish the bacterial aetiology of the malabsorption and to obtain information about the causative microorganisms. A broad-spectrum antibiotic, chlortetracycline, was compared with virginiamycin, which is active only against Gram-positive microorganisms. The antibiotics were mixed with the diet at a concentration of 200 parts per million and were fed to control and blind loop rats for one week. Faecal total and free fatty acids were then measured, and the results are given in Figure 2.

Virginiamycin given orally lowered the faecal fat excretion of rats with blind loops and cured the malabsorption; faecal output per day was also reduced. Chlortetracycline had less or no effect on the amount of faecal fat in control and blind loop rats, but caused a decrease in the percentage of free fatty acids; $78 \%$ of faecal fatty acids of blind loop rats on a normal diet were free, and only $18 \%$ when the rats were fed a chlortetracycline-supplemented diet. This could be due to inhibition of intestinal lipase by chlortetracycline (Krondl, Vokáč, and Vavřínková, 1962).

BACTERIOLOGICAL RESULTS Only preliminary results of the bacteriological examinations have been obtained. A profuse flora, $10^{9}$ organisms per millilitre content, was found in the blind loop and in the small intestine distal to the blind loop, whereas in a normal intestine $10^{3}-10^{4}$ organisms per millilitre are commonly enumerated. According to inoculations on different media, there are at least $\mathbf{1 0}$ times as many anaerobic as aerobic bacteria in the blind loop. Both Gram's stains and cultures revealed a predominance of Gram-positive organisms: streptococci (enterococci), lactobacilli, and anaerobic rods identified as Clostridium welchii.

The same procedure was followed for blind loop

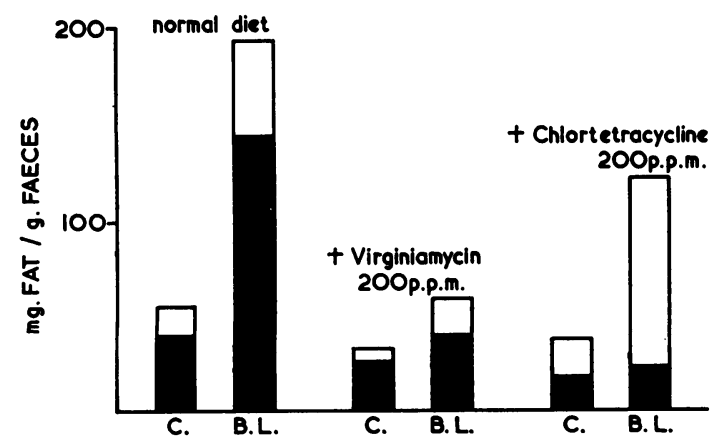

FIG. 2. Faecal fat in control and blind loop rats on $9 \%$ corn-oil and antibiotic-supplemented diets. $C=$ control rats; B.L. = blind loop rats; black area indicates free fatty acids. rats receiving a virginiamycin-supplemented diet and with fat excretion lowered to normal levels. The number of Gram-negative microorganisms increased with a corresponding decrease in Gram-positives; the anaerobic bacillus, Clostridium welchii, could no longer be seen or cultured. No important difference was noticed in the bacteriology of the blind loop in rats fed a normal or a chlortetracycline-supplemented diet.

HISTOLOGY The sections of stomach appeared quite normal and no signs of inflammation or degeneration were found. The histological structure of the small intestine was normal (Fig. 3) in nearly all rats examined. Only occasionally slight broadening of the villi and a mild degree of round-cell infiltration was seen in an intestinal fragment. Sections through the blind loop showed a characteristic hypertrophy of the muscularis mucosae (Figs. 4 and 5). The other coats (Fig. 4) were also commonly hypertrophied (Cameron, et al. 1950); this was not a general phenomenon, since villous atrophy and tortuously structured villi (Fig. 5) were occasionally seen. In no case could we demonstrate the presence of an entirely flat and featureless mucosa as found in different types of malabsorption syndrome (Wolstenholme and Cameron, 1962). On Gram's stain a great number of Gram-positive bacteria were found (Fig. 6) close to the epithelium of the blind loop and in the intervillous space. However, no bacterial invasion through the epithelium was recorded.

\section{DISCUSSION}

Both the fat content of the faeces and the daily faecal output were increased in rats with an intestinal cul-de-sac. These findings, reported in Table II, are important, since in humans the diagnosis of steatorrhoea is established only when both values are increased above normal (Hendry, 1960).

Fat absorption in the rat is most seriously impaired when the blind loop is in the proximal part of the small intestine. This correlates with studies in normal rats, where the jejunum is the normal site of fat absorption (Booth, Read, and Jones, 1961). In clinical cases of blind loop syndrome, too, steatorrhoea occurs preferentially when the anatomical defect is in the proximal part of the small intestine (Schiffer, Faloon, Chodos, and Lozner, 1962).

This steatorrhoea is due mainly to malabsorption of alimentary fats (Fig. 1), as in clinical cases of nontropical sprue (Blomstrand, 1955). But faecal lipids of non-dietary origin are also increased in blind loop rats, as shown by the higher fat excretion even on a 


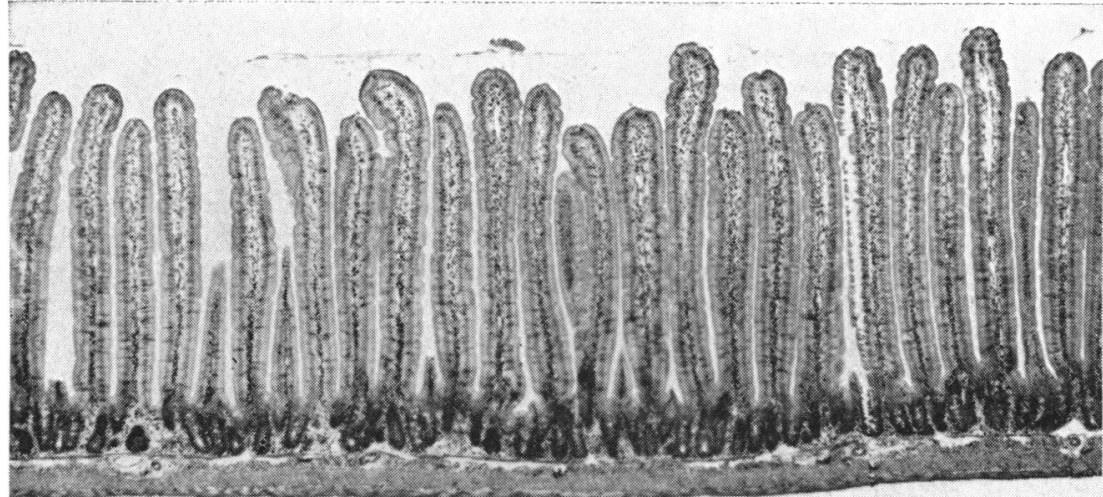

FIG. 3. Jejunum of

normal rat.

Haematoxylin and eosin $\times 50$.

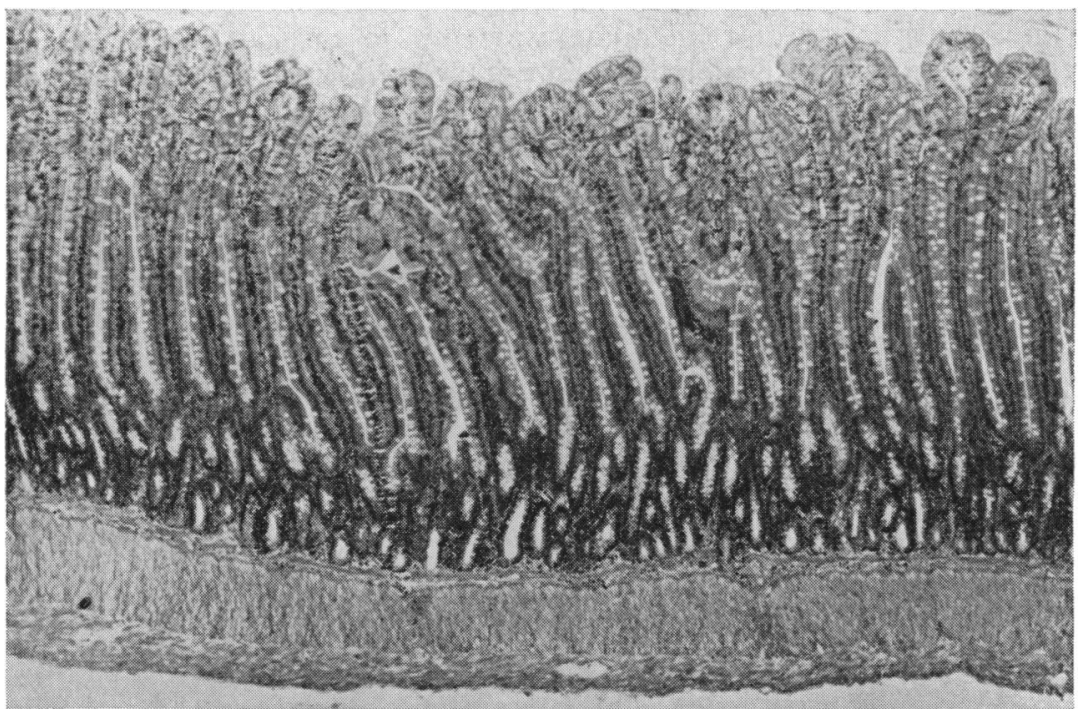

FIG. 4. Section of blind loop. Hypertrophy of all the coats. Haematoxylin and eosin $\times 40$.

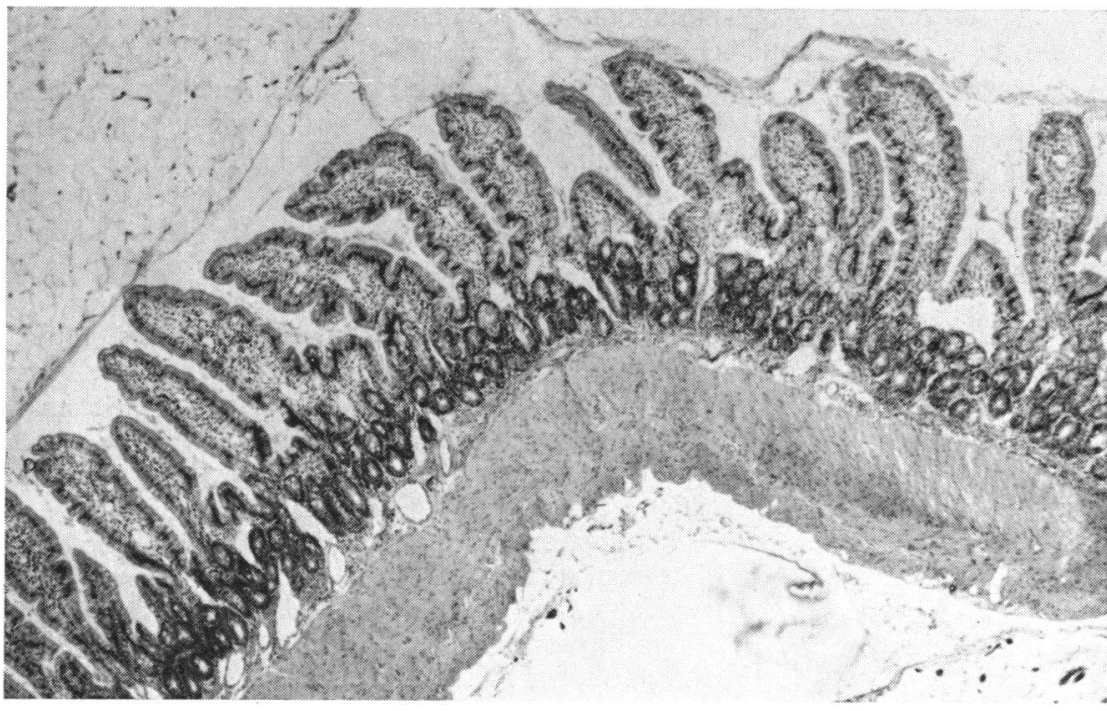

FIG. 5. Section of blind loop. Hypertrophy of the muscularis mucosae, tortuous aspect of the villi. Haematoxylin and eosin $\times 50$. 


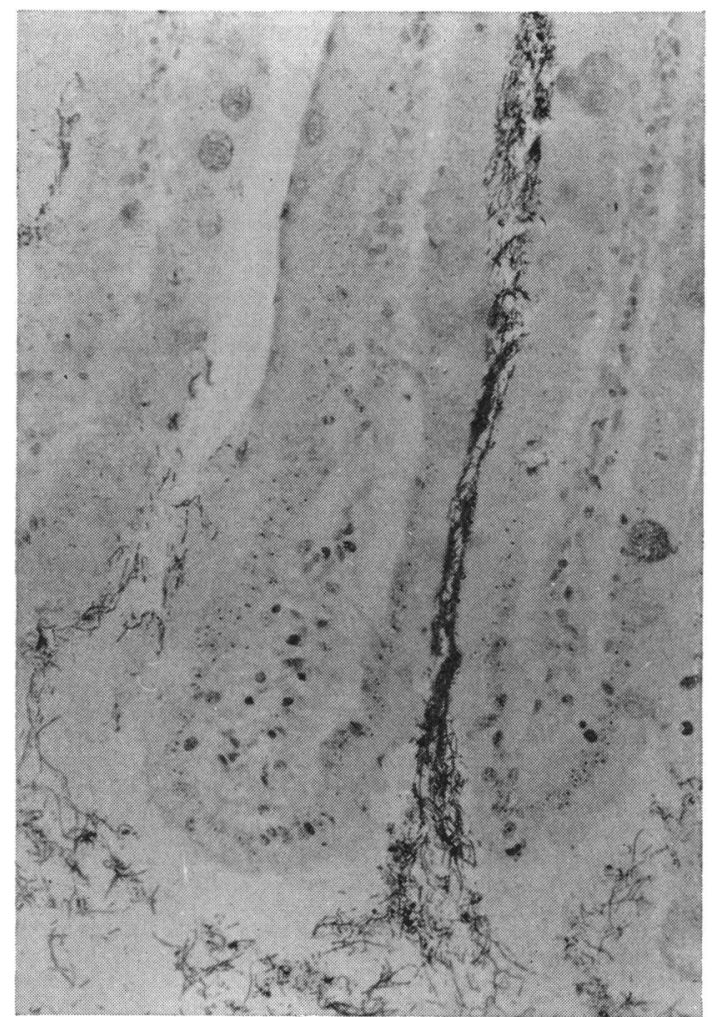

FIG. 6. Section of blind loop. Gram-positive bacteria in the gut lumen and intervillous space. Gram's stain $\times 400$.

fat-free diet. This faecal lipid of non-dietary origin in operated rats is probably not derived from bacteria of the blind loop, excreted with the gut contents, since faecal free fatty acids containing the peculiar 'microbial' fatty acids are not increased. The difference in fat excretion between control and blind loop rats on a fat-free diet is due to esterified fatty acids representing possibly endogeneous lipids (mucosal desquamation, secretion) which were not reabsorbed. According to our results, both absorption of alimentary fat and reabsorption of endogenous lipids are impaired in the blind loop rat.

The therapeutic effect of antibiotics on the steatorrhoea shows the bacterial aetiology of the blind loop syndrome. The causative microorganisms could be Gram-positive, since we found a predominance of anaerobic Gram-positive microbes in the lumen of the gut of blind loop rats and since their steatorrhoea was cured by an antibiotic active only against Gram-positive microbes. This could be related to the disappearance of Clostridium welchii from the intestinal lumen. When fed a chlortetracycline-supplemented diet, blind loop rats still excreted more fat than control animals; Clostridium welchii could be cultured from the gut contents under these conditions. This is in contrast to the therapeutic effect of chlortetracycline in humans with a blind loop syndrome, in whom the use of a massive dose of a broad-spectrum antibiotic does not permit any conclusion as to the nature of the responsible microorganisms.

Although some evidence is presented in favour of Clostridium welchii as the organism responsible for the increased fat excretion, no definite conclusion can be drawn from the present investigation. Our experiments, however, are in close agreement with the studies on the effect of antibiotics on intestinal flora in other animals. Intestinal absorption of nutrients in chickens is improved by virginiamycin, in association with its growth-stimulating effect (Eyssen and De Somer, 1963). The studies of Lev and Forbes (1959) suggest that antibiotics could achieve this by their antibacterial action against the clostridia of the intestine, because these microbes, when given orally to germ-free chickens, lowered the growth rate of the birds.

The mechanism of action of microorganisms on fat absorption is only speculative. Clostridium welchii could impair fat absorption in the rat through the lecithinase $\mathrm{C}$ synthesized by their organism or through a product of the enzymatic breakdown of lecithine, phosphorylcholine for instance (Nygren, 1962). Nevertheless, in preliminary experiments, cultures of Clostridium welchii, lecithinase C (Sigma Chem.), or phosphorylcholine (Sigma Chem.) fed to normal rats did not influence the faecal fat excretion.

In a study on the role of bile salts, Dawson and Isselbacher (1960) suggested that microbes from the blind loop may deconjugate bile salts and that free bile acids could produce toxic degeneration of small intestinal mucosa with impairment of intracellular esterification of fatty acids. This hypothesis would be in agreement with the observations that different strains of clostridia (and enterococci) split the peptide bond of conjugated bile acids (Norman and Grubb, 1955). The degradation by bacteria of cholic acid to deoxycholic acid (Norman and Sjövall, 1958) could also impair fat absorption.

The mucosa of the small intestine was histologically unaltered and the malabsorption was associated with only limited changes of the blind loop mucosa. The possible importance of bacterial invasion of the intestinal wall has recently been discussed by Dixon and Paulley (1963). Since we did not observe invasion of the villi by micrcorganisms (Fig. 6), steatorrhoea might be due either to bacterial toxins penetrating mucosal cells and acting upon their enzymes without consistent histological modifications, or to the composition of 
the gut contents modified by the microorganisms. Work is in progress to establish the exact role of clostridia and other bacterial strains in the malabsorption associated with the blind loop syndrome.

The histological study was done by Dr. M. Vandeputte at the Rega Institute for Medical Research. We are grateful to him for his contribution and his interest in this work.

\section{REFERENCES}

Aitken, M. A., Badenoch, J., and Spray, G. H. (1950). Fat excretion in rats with intestinal culs-de-sac. Brit. J. exp. Pathol., 31, 355-357.

Badenoch, J. (1960). Steatorrhoea in the adult. Brit. med. J., 2, 879-887; $963-974$.

Blomstrand, R. (1955). A study on the intestinal absorption of fat in normal adults and in non-tropical sprue with carbon-labelled oleic acid and palmitic acid. Acta med. scand., 152, 129-138.

Booth, C. C., Read, A. E., and Jones, E. (1961). Studies on the site of fat absorption. Gut, 2, 23-31.

Cameron, D. G., Watson, G. M., and Witts, L. J. (1949). The experimental production of macrocytic anaemia by operations on the intestinal tract. Blood, 4, 803-815.

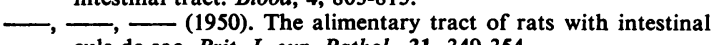
culs-de-sac. Brit. J. exp. Pathol., 31, 349-354.

Cooke, W. T., Cox, E. V., Fone, D. J., Meynell, M. J., and Gaddie, R. (1963). The clinical and metabolic significance of jejunal diverticula. Gut, 4, 115-131.

Dawson, A. M., and Isselbacher, K. J. (1960). Studies on lipid metabolism in the small intestine with observations on the role of bile salts. J. clin. Invest., 39, 730-740.

Dixon, J. M. S., and Paulley, J. W. (1963). Bacteriological and histological studies of the small intestine of rats treated with mecamylamine. Gut, 4, 169-173.
Dole, V. P., and Meinertz, H. (1960). Microdetermination of longchain fatty acids in plasma and tissues. J. biol. Chem., 235 , 2595-2599.

Edwards, H. M., Jr., and Gillis, M. B. (1959). A chromic oxide balance method for determining phosphate availability. Poultry Sci., 38, 569-574.

Evrard, E., Hoet, P. P., Eyssen, H., Charlier, H., and Sacquet, E. (1964). Faecal lipids in germ-free and conventional rats. To be published.

Eyssen, H., and De Somer, P. (1963). The mode of action of antibiotics in stimulating growth of chicks. J. exp. Med., 117, 127-138.

Gellman, D. D. (1956). Diverticulosis of the small intestine with steatorrhoea and megaloblastic anaemia. Lancet, 2, 873-874.

Goldstein, F., Wirts, C. W., and Kramer, S. (1961). The relationship of afferent limb stasis and bacterial flora to the production of post-gastrectomy steatorrhoea. Gastroenterology, 40, 47-55.

Hendry, E. B. (1960). The chemical diagnosis of steatorrhoea. Brit. med. J., 2, 975-979.

Kamer, J. H., van de, ten Bokkel Huinink, H., and Weyers, H. A. (1949). Rapid method for the determination of fat in faeces. J. biol. Chem., 177, 347-355.

Krondl, A., Vokáč, V., and Vavřinková, H. (1962). Influence of chlortetracycline and neomycin on digestion and absorption of fat in rats. Amer. J. Physiol., 202, 437-439.

Lev, M., and Forbes, M. (1959). Growth response to dietary penicillin of germ-free chicks and of chicks with a defined intestinal flora. Brit. J. Nutr., 13, 78-84.

Norman, A., and Grubb, R. (1955). Hydrolysis of conjugated bile acids by Clostridia and enterococci. Acta pathol. microbiol. scand., 36, 537-547.

_, and Sjövall, J. (1958). On the transformation and enterohepatic circulation of cholic acid in the rat. J. biol. Chem., 233, 872-884.

Nygren, B. (1962). Phospholipase C-producing bacteria and food poisoning. Acta pathol. microbiol. scand., suppl., 160.

Schiffer, L. M., Faloon, W. W., Chodos, R. B., and Lozner, E. L. (1962). Malabsorption syndrome associated with intestinal diverticulosis. Gastroenterology, 42, 63-68.

Wirts, C. W., and Goldstein, F. (1963). Studies on the mechanism of post-gastrectomy steatorrhoea. Ann. intern. Med., 58, 25-26.

Wolstenholme, G. E. W., and Cameron, M. P. (1962). Intestinal Biopsy. (Ciba Foundation Study Group, No. 14.) Churchill, London. 